\title{
The epistemology of quality improvement: it's all Greek
}

\author{
Rocco J Perla, ${ }^{1,2}$ Gareth J Parry ${ }^{3,4}$
}

\begin{abstract}
${ }^{1}$ Center for Innovation and Transformational Change, UMass Memorial Health Care, Worcester, Massachusetts, USA ${ }^{2}$ UMass Medical School, Worcester, Massachusetts, USA

${ }^{3}$ Institute for Healthcare Improvement, Cambridge, Massachusetts, USA ${ }^{4}$ Harvard Medical School, Boston, Massachusetts, USA

Correspondence to Gareth J Parry, Institute for Healthcare Improvement, 20 University Road, 7th Floor, Cambridge, MA 02138, USA; gparry@ihi.org
\end{abstract}

Accepted 24 October 2010

\section{ABSTRACT}

In Plato's Theaetetus, knowledge is defined as the intersection of truth and belief, where knowledge cannot be claimed if something is true but not believed or believed but not true. Using an example from neonatal intensive care, this paper adapts Plato's definition of the concept 'knowledge' and applies it to the field of quality improvement in order to explore and understand where current tensions may lie for both practitioners and decision makers. To increase the uptake of effective interventions, not only does there need to be scientific evidence, there also needs to be an understanding of how people's beliefs are changed in order to increase adoption more rapidly. Understanding how best to maximise the overlap between actual and best practice is where quality improvement needs to employ educational and social sciences' methodologies and techniques.

\section{THE STAGE IS SET}

An infant born at 26 weeks' gestation is admitted to a neonatal intensive care unit. The care team prepares to carry out recommended best practice, including administering surfactant therapy. However, a nurse on the care team has just read the results of a randomised controlled trial published in the New England Journal of Medicine indicating that premature infants receiving early continuous positive airway pressure (CPAP) rather than surfactant are likely to survive, but have a lower risk of adverse neonatal outcomes. ${ }^{1}$ The nurse has worked with the study authors before, strongly believes in the results and suggests to the care team that the infant be given CPAP rather than surfactant. However, the rest of the care team decides to continue with their usual practice of administering surfactant therapy.

This paper is freely available online under the BMJ Journals unlocked scheme, see http://qualitysafety.bmj. com/site/about/unlocked. xhtml

\section{VIEWS OF KNOWLEDGE}

The local decision-making dilemma described above is common in healthcare. A constantly growing information base leads to great challenges for clinicians to keep their understanding and practices current. Competing views and findings together with the time it takes for innovations to find their way into routine clinical practice only add to the challenges. ${ }^{2}$ Before returning to our NICU decision above, we explore some fundamental concepts in epistemology dating back to Plato's first works on the subject through more modern interpretations to show how these ideas are still relevant and applicable to modern practitioners who want to engage with the improvement agenda and yet frequently operate under information overload and conflicting data.

\section{EPISTEMOLOGY AND JUSTIFIED TRUE BELIEF}

Epistemology is a branch of philosophy generally concerned with the nature of knowledge. ${ }^{3}$ It asks questions such as 'How do we know?' and 'What is meaningful knowledge?'. Understanding what it means to have knowledge in a particular area-and the contexts and warrants that shape knowledgehas been a fundamental quest for centuries. In Plato's Theaetetus, knowledge is defined as the intersection of truth and belief-referred to classically as justified true belief (JTB). ${ }^{4}$ Here, knowledge cannot be claimed if something is true but not believed or believed but not true (ie, lacking justification). For example, in a Platonic sense, it may be considered true that good hand hygiene reduces infection rates. If a practitioner believes good hand hygiene will lead to fewer hospital-acquired infections as judged by their actions, then they would have knowledge.

In its purest form, the idea of JTB would not seem particularly practical or germane to efforts to improve the quality of patient care, largely because science and medicine do not seek absolute truths in a Platonic sense, nor can we always assess our theories and views 
with absolute certainty. The educational philosopher John Dewey defined knowledge as the 'Conscious and voluntary effort to establish belief upon a firm basis of reasons'. ${ }^{5}$ Dewey's definition seems to fit well with the practice of modern medicine-or does it? Indeed, it is likely that almost all healthcare professionals will claim that their beliefs and clinical practice are grounded upon a firm basis of reasons. However, we know many patients receive care and treatment that is inconsistent with the best available evidence. ${ }^{6}$ There is always going to be a healthy debate about what constitutes a firm basis of reasons, or best evidence. However, if we can identify situations where the evidence is valid, reliable, compelling and generalisable, then we should expect the actions of healthcare professionals to reflect and represent that evidence consistently and reliably. The high level question facing most healthcare systems and leaders today is how can they design knowledgeable healthcare systems that maximise the alignment between the current best evidence ('truth') and the actions of healthcare providers ('belief')? Leaders must also recognise that individual and group beliefs and behaviours exist within systems of care where attempts to act on the best clinical evidence base are often thwarted by systems poorly designed to deliver such care consistently.

One approach is to think carefully about what knowledge is and to use simple models and heuristics as starting points for reflection, learning and discussion. Simple (action-oriented) models can help make what is implicit and variable, explicit and systematic. From Plato to the modern era, the label of knowledge has required the demonstration of some action or application characteristic. In fact, application is a higher order function in Bloom's Taxonomy of learning. ${ }^{7}$ As Hawthorne and Stanley point out, 'the value of knowledge is due in part to its role as a norm for action'. ${ }^{8}$ For example, virtually all medical students are required to undergo some form of apprenticeship, clinical rotation or residency. The purpose of these experiences is for the student to demonstrate the ability to transfer their didactic training into observable actions (competencies) that are the basis of assessing performance and continued learning. The healthcare student demonstrating outstanding performance in the classroom, but who cannot execute and practise their trade (such as phlebotomy or inserting a central venous catheter) may not be considered knowledgeable. To say someone 'knows' how to perform a task when they cannot execute the task in practice may be an example of what the philosopher Wittgenstein would call a 'language trap'.

\section{DEGREES OF BELIEF AND EVIDENCE}

The Venn diagram in figure 1 is a modification of Plato's JTB concept which relaxes the notion of truth and

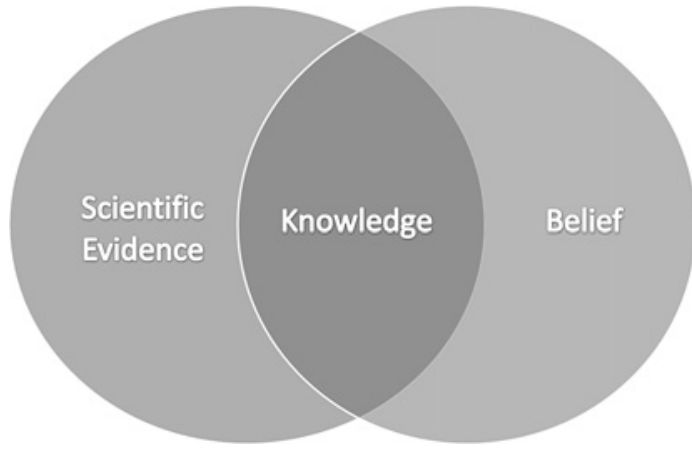

Figure 1 An illustration of a modified version of Plato's Justified True Belief.

provides a way to model knowledge by emphasising the interaction of belief (demonstrated through action) and scientific evidence. The diagram replaces the Platonic notion of truth with scientific evidence and thereby defines knowledge as the intersection of belief and scientific evidence. By this definition, someone who believes something not grounded in scientific evidence (Dewey's firm basis of reason) cannot have knowledge. Conversely, someone who understands and has been exposed to scientific evidence, but does not believe in it (as judged by their actions) also cannot be said to have knowledge.

This is, of course, an over-simplification of knowledge since there are degrees of belief and evidence. Ideally, a clinician would hope that their degree of belief for an intervention or treatment would be strongest for those interventions with the strongest evidence of success. Similarly, regulatory and accrediting bodies are usually very careful to make sure that the indicators they use are agreed upon, stable, scientifically sound and relatively non-controversial. ${ }^{10}$ Once selected, the entire process of inspections and audits is intended to assess the alignment or overlap of best practice with actual practice.

\section{QUALITY IMPROVEMENT KNOWLEDGE}

Improvement science has long recognised the concept of JTB, even if it has not explicitly or clearly acknowledged this. The idea that knowledge is not simply information about the best scientific evidence, but rather the intersection of belief (as demonstrated by action) and the best available scientific evidence lies at the heart of quality improvement. The 'Will, Ideas and Execution' framework promoted by the Institute for Healthcare Improvement underlines the importance of action or 'Execution' as a fundamental component of improvement knowledge. ${ }^{11}$ Often in quality improvement efforts, rigorous and generalisable scientific evidence is not available and the notion of generalisable scientific evidence may be replaced by 'Ideas' applicable 
to a local setting by those closest to the process or system being improved. For example, an improvement team looking to decrease wait times in their Emergency Ward will have local knowledge of the system, practice patterns, staff and services that are most likely to impact delays and would need to use this information to drive behaviour as they test different changes with the goal of reducing wait times. This local knowledge, perhaps not generalisable, is still reliable and valid and can serve as a guide to action, learning and improvement. Organisations may have the will to change, ideas on how to make things better, but often struggle with execution. ${ }^{12}$ Further, at the heart of the Deming-inspired Model for Improvement lies the Plan-Do-Study-Act (PDSA) cycle developed to build knowledge and to facilitate system improvements. ${ }^{13} 14$ Initially, a PDSA cycle aims to have people test a small change idea in a 'safe' setting. The model aims to provide people with direct experience of whether or not a small change works in their setting - that is, to specifically build their understanding (combination of prediction, data and experience) and then to start expanding the testing as their understanding grows. When efforts are made to spread this understanding and learning across an organisation or across a number of organisations problems frequently occur. For example, little attention is often paid to the beliefs of people in the new setting, leading to poor adoption of the apparently effective change. ${ }^{15}$ It may be important in increasing adoption of scientifically grounded or promising local initiatives to pay attention to increasing the understanding of people in a new setting by, for example, continuing to facilitate the introduction of changes in a small, safe and testable manner. Such an approach of testing and careful implementation and spread can lead to the creation of a knowledgeable healthcare system.

In simplistic terms, it can be argued that the generalisable scientific evidence of clinical interventions comes from the clinical effectiveness research community and an understanding of how the belief (or uptake) in these interventions can be accelerated comes from the social sciences. However, it is clear that the science of quality improvement must learn and apply methods from both clinical research and the social sciences if it is to understand how best to maximise the overlap between 'truth' and 'belief' and to accelerate the rate of learning and improvement.

\section{SURFACTANT OR CPAP?}

Returning to the infant described at the start of the paper, it is worth considering to what degree best practice and actual practice overlapped. The standard practice was to administer surfactant therapy. At least one member of the care team described a new scientific study demonstrating CPAP to be more effective. However, the clinical team decided to maintain current practice and to administer surfactant. Following the model described in this paper, the one nurse suggesting the use of CPAP may have demonstrated understanding of the scientific evidence base, however, because the rest of the clinical team have experienced positive results when administering surfactant, they do not have sufficiently strong belief in the use of CPAP to change their current practice. To the extent that the use of CPAP at that time could be viewed as the best clinical approach for this patient based on the most current evidence available, the team was not knowledgeable as their beliefs and subsequent actions did not overlap with this evidence base. Of course, the process by which the care team over-rode the arguments of the nurse and chose surfactant rather than CPAP are important to consider. From rapid response teams to care bundles, there are some situations where the evidence base is at times unclear and a single agreed upon standard may not yet exist. In such cases, the model outlined here would include competing views that each have a degree of scientific support. The aim of the model is not to select a best standard from legitimate competing views, but rather to isolate situations where belief and action are inconsistent with a clearly identified best practice and to use this 'alignment' assessment as a guide to improved care processes. In situations where clear and compelling evidence for a standard does not exist, the goal is to define a reasonable 'standard in use' for the purpose of initiating systematic and rapid testing and learning. The challenge of quality improvement is to figure out how to maximise the overlap between ever-changing evidence and practitioners' belief in the evidence in order to build more knowledgeable healthcare systems, within complex team and power dynamics. ${ }^{16}$

\section{CONCLUSIONS}

The model of improvement knowledge outlined here, borrowed from the Greeks and extended by learning theorists, places a premium on action as well as learning and reflection. It is important within quality improvement for a number of reasons. First, it shifts the concept of knowledge away from the purely didactic, procedural and passive form of practice to an action-oriented model where rapid testing and learning dominate. Second, it supports a wide range of healthcare-related activities from improvement work to accountability models by identifying a common goal: maximising the overlap between what we think is the best way of doing something and what is actually done in practice. This goal is also an important aspect of translational research. ${ }^{17}$ 
Third, it clearly recognises that regulatory standards and improvement initiatives alike must account for the beliefs of the healthcare professionals in a particular setting and address the factors that shape what people actually do, not simply telling them, or mandating, what they should be doing. In particular, improvement involves change and this model underlines that change requires engaging with people's current beliefs and finding ways in which people can test and learn from their own experience of whether something new works or not and to what degree. Understanding how best to maximise the overlap between actual and best practice is where quality improvement needs to employ educational and social sciences' methodologies and techniques.

Funding Health Foundation.

Competing interests None declared.

Provenance and peer review Not commissioned; externally peer reviewed.

\section{REFERENCES}

1. SUPPORT Study Group of the Eunice Kennedy Shriver NICHD Neonatal Research Network. Early CPAP versus surfactant in extremely preterm infants. N Engl J Med 2010;362:1970-9.

2. Balas $\mathrm{E}$, Boren $\mathrm{S}$, eds. Managing clinical knowledge for health care improvement. In: Bemmel J, McCray A, eds. Yearbook of Medical Informatics. Bethesda, Md: National Library of Medicine, 2000.

3. Feldman R. Epistemology. Prentice Hall, 2002.
4. Cornford FM. Plato's theory of knowledge: The theaetetus and the sophist. Dover Publications, 2003. Original author, Plato. (Trans).

5. Dewey J. How we think. Dover Publications, 1997 (originally published 1910).

6. McGlynn EA, Asch SM, Adams J, et al. The quality of health care delivered to adults in the United States. $N$ Engl $J$ Med 2003;348:2635-45.

7. Anderson LW, Krathwohl DR, Airasian PW, et al. A taxonomy for learning, teaching, and assessing: A revision of Bloom's taxonomy of educational objectives, abridged edition. Allyn \& Bacon, 2000.

8. Hawthorne J, Stanley J. Knowledge and action. J Philos 2008:10:571-90.

9. Wittgenstein L. Philosophical investigations. New York: Macmillan Company, 1965.

10. Chassin MR, Loeb JM, Schmaltz SP, et al. Accountability measures-Using measurement to promote quality improvement. N Engl J Med 2010;363:683-8.

11. Nolan TW. Execution of Strategic Improvement Initiatives to Produce System-Level Results. IHI Innovation Series white paper. Cambridge, MA: Institute for Healthcare Improvement, 2007. http://www.IHI.org.

12. Oxman AD, Thomson MA, Davis DA, et al. No magic bullets: a systematic review of 102 trials of interventions to improve professional practice. CMAJ 1995;153:1423-31.

13. Langley GL, Nolan KM, Nolan TW, et al. The Improvement Guide: A Practical Approach to Enhancing Organizational Performance. 2nd edn. San Francisco, California, USA: Jossey-Bass Publishers, 2009.

14. Deming WE. The New Economics for Industry, Government Education. 2nd edn. Boston, USA: MIT Press, 2000.

15. Greenhalgh T, Robert G, Macfarlane F, et al. Diffusion of innovations in service organizations: systematic review and recommendations. Milbank Q 2004;82:581-629.

16. Flyvbjerg B. Making Social Science Matter: Why Social Inquiry Fails and How it Can Succeed Again. Cambridge: Cambridge University Press, 2001.

17. Woolf $\mathrm{SH}$. The meaning of translational research and why it matters. JAMA 2008;299:211-13. 